\title{
Long-term persistence of neutralizing memory B cells in SARS-CoV-2
}

Rowena Bull ( $\square$ r.bull@unsw.edu.au )

University of New South Wales

Arunasingam Abayasingam

University of New South Wales

Harikrishnan Balachandran

University of New South Wales

David Agapiou

University of New South Wales

Chaturaka Rodrigo

University of New South Wales

Elizabeth Keoshkerian

University of New South Wales

Hui Li

University of New South Wales

Nicholas Brasher

University of New South Wales

Daniel Christ

Antibody Therapeutics Group, Immunology Division, Garvan Institute of Medical Research and St

Vincent's Clinical School, Faculty of Medicine, The University of New South Wales Sydney

\section{Romain Rouet}

Garvan Institute of Medical Research

Deborah Burnett

Garvan Institute of Medical Research

\section{Branka Grubor-Bauk}

The University of Adelaide

\section{William Rawlinson}

Virology Research Laboratory

\section{Stuart Turville}

UNSW Sydney

\section{Anupriya Aggarwal}

UNSW Sydney

\section{Fabienne Brilot}

University of Sydney 


\section{Michael Mina}

Northern Beaches Hospital

Jeffrey Post

Prince of Wales Clinical School, UNSW https://orcid.org/0000-0003-1475-9272

\section{Bernard Hudson}

Royal North Shore Hospital

\section{Nicky Gilroy}

Westmead Hospital

\section{Dominic Dwyer}

New South Wales Health Pathology

\section{Sarah Sasson}

University of New South Wales

\section{Fiona Tea}

University of Sydney

\section{Deepti Pilli}

University of Sydney

\section{Nicodemus Tedla}

University of NSW

\section{Andrew Lloyd}

UNSW Australia https://orcid.org/0000-0001-6277-8887

Marianne Martinello

Kirby Institute, UNSW Sydney, Sydney

\section{Article}

Keywords: SARS-CoV-2, neutralising antibodies, RBD, memory B cells

Posted Date: October 28th, 2020

DOl: https://doi.org/10.21203/rs.3.rs-92527/v1

License: (c) (i) This work is licensed under a Creative Commons Attribution 4.0 International License. Read Full License 
2 Arunasingam Abayasingam*1,2, Harikrishnan Balachandran*1,2, David Agapiou ${ }^{2}$, 3 Chaturaka Rodrigo ${ }^{1,2}$, Elizabeth Keoshkerian ${ }^{2}$, Hui $\mathrm{Li}^{2}$, Nicholas A Brasher ${ }^{1,2}$, Daniel 4 Christ $^{3}$, Romain Rouet ${ }^{3}$, Deborah Burnet ${ }^{3}$, Branka Grubor-Bauk ${ }^{4}$, William Rawlinson ${ }^{1,5}$, 5 Stuart Turville ${ }^{2}$, Anupriya Aggarwal ${ }^{2}$, Fabienne Brilot ${ }^{6,7}$, Michael Mina ${ }^{8}$, Jeffrey J Post ${ }^{9}$, 6 Bernard Hudson ${ }^{10}$, Nicky Gilroy ${ }^{11}$, Dominic Dwyer ${ }^{11}$, Sarah Sasson ${ }^{2}$, Fiona Tea ${ }^{6,7}$, Deepti 7 Pilli $^{6,7}$, Nicodemus Tedla ${ }^{1}$, Andrew R Lloyd ${ }^{2}$, Marianne Martinello ${ }^{+2,11}$, Rowena A 8 Bull $^{+1,2}$ and on behalf of the COSIN study group.

${ }^{1}$ School of Medical Sciences, Faculty of Medicine, UNSW Australia, Sydney, NSW, Australia,

${ }^{2}$ The Kirby Institute, UNSW Australia, Sydney, NSW, Australia,

${ }^{3}$ Garvan Institute of Medical Research, 384 Victoria Street, Darlinghurst, New South Wales 2010, Australia.

${ }^{4}$ Virology Laboratory, Discipline of Surgery, The University of Adelaide and Basil Hetzel Institute for Translational Health Research, Adelaide 5011, Australia

${ }^{5}$ Serology and Virology Division, Department of Microbiology, NSW Health Pathology, Prince of Wales Hospital, Sydney, New South Wales, Australia

${ }^{6}$ Faculty of Medicine and Health, School of Medical Sciences, The University of Sydney, Sydney, NSW, Australia

${ }^{7}$ Brain Autoimmunity Group, Kids Neurosciences Centre, Kids Research at the Children's Hospital at Westmead, Sydney, New South Wales, Australia

${ }^{8}$ Northern Beaches Hospital, NSW, Australia

${ }^{9}$ Prince of Wales Clinical School, UNSW Australia, Sydney, NSW Australia

${ }^{10}$ Royal North Shore Hospital, Sydney, New South Wales, Australia

${ }^{11}$ Westmead Hospital, Sydney, New South Wales, Australia

${ }^{12}$ Blacktown Mt Druitt Hospital, Blacktown, NSW, Australia

* Both authors contributed equally; +Corresponding authors

\section{Highlights}

- Longitudinal monitoring of 81 people with SARS-COV-2 infection for antigen binding and viral neutralisation

- Significant reduction of antibody binding to RBD and spike antigen after six months

- 35 of 81(43\%) participants had reverted to background neutralising levels

- Despite reduced antibody titres, robust memory B cell populations were observed

- Memory B cells retained neutralising capacity

\section{Summary}

Considerable concerns relating to the duration of protective immunity against SARSCoV-2 have been raised, with evidence of antibody titres declining rapidly after infection and reports of reinfection. Here we monitored antibody responses against SARS-CoV-2 receptor binding domain (RBD) for up to six months after infection. While antibody titres were maintained, half of the cohort's neutralising responses had returned to background. However, encouragingly in a selected subset of 13 participants, 12 had detectable RBD-specific memory B cells and these generally increased out to 6 months. Furthermore, we were able to generate monoclonal antibodies with SARSCoV-2 neutralising capacity from these memory B cells. Overall our study suggests that the loss of neutralising antibodies in plasma may be countered by the maintenance of neutralising capacity in the memory B cell repertoire.

Key words: SARS-CoV-2, neutralising antibodies, RBD, memory B cells 
2 Virus and host immune factors impact on the severity of acute infection, and the 3 subsequent quality and durability of immunological memory that will be established to 4 protect against reinfection. ${ }^{1}$ In SARS-CoV-2 infection, at least $80 \%$ of people infected unwell, with hyperactivation of the immune system leading to excessive production of pro-inflammatory cytokines, lymphopenia, development of acute lung injury, and other end organ damage..$^{2-4}$ Age and disease severity have been linked with higher antibody titres and virus-specific neutralising activity, ${ }^{5}$ and it has been suggested that antibody responses may wane more quickly following mild illness, ${ }^{6}$ although not all studies support these observations. ${ }^{7}$

As the COVID-19 pandemic continues to spread, the development of a prophylactic vaccine is critical. ${ }^{8}$ A key component underpinning a successful vaccine design is an understanding of the characteristics of naturally-occurring, potentially protective immunity. This includes both the immunological correlates of initial control of viral replication, and the factors supporting establishment and long-term maintenance of adaptive immune responses. Evidence suggests that virus-specific B cell responses in people with SARS-CoV-2 infection occur in conjunction with $\mathrm{CD} 4^{+} \mathrm{T}$ follicular helper cell responses from around one week after symptom onset. ${ }^{9-11}$ The first antibody responses target the $\mathrm{N}$ protein, whereas antibodies recognising the $\mathrm{S}$ protein occur approximately one week later. Neutralising antibody (NAb) responses, predominantly directed against the receptor binding domain (RBD) of the S protein, develop within 2-3 weeks. ${ }^{12}$ Most studies report very high rates of seroconversion to SARS-CoV-2, ${ }^{5,13,14}$ followed by a rapid decline in RBD-specific antibody titres. ${ }^{5,13}$ However, to-date most of these studies have only reported up to four months following infection.

In SARS-CoV-1 infection, durability of the antibody response is relatively short, with the initial specific IgG and NAb titres falling progressively over 2-3 years to become undetectable in up to $25 \%$ of individuals. ${ }^{15}$ Short-lived NAb responses may not be a problem if robust memory $\mathrm{B}$ cell responses are generated and can be re-activated upon reinfection. However, memory B cell responses in SARS-CoV-1 may also be shortlived ${ }^{10}$. To date, only two studies have examined the SARS-CoV-2-specific memory B cell response beyond four months. ${ }^{16,17}$ Encouragingly, both these studies report that SARS-CoV-2-specific memory B cells are maintained but no studies have yet reported whether these memory B cells present several months after infection can generate neutralising antibodies upon reinfection.

In this study we examined longitudinal antibody responses (anti-RBD, anti-spike, and inhibitory capacity against a 50\% infective dose [ID50]) among 81 people with SARSCoV-2 infection (confirmed by nucleic acid amplification testing [NAT]) at two time windows 1-3 and 4-6 months following symptom onset. We also assessed correlations between antibody titres in the blood and RBD-specific memory B cell frequency and the capacity of these memory B cells to make neutralising antibodies.

\section{Results}

Participants

Anti-RBD titres and neutralising activity were analysed in 81 participants at two followup time points ( $\mathrm{t} 1$ and $\mathrm{t} 2$ ), calculated from the days post symptom onset (DPS). Across all participants $\mathrm{t} 1$ ranged from 30 - 87 DPS (median: 68, interquartile range [IQR]: 61 79 days) and t 2 ranged from $110-181$ DPS (median: 132, IQR: $118-151$ days). The median time between sampling points ( $\mathrm{t} 2$-t 1 ) was 65 days (range: $31-126$ days, IQR: 52 - 89 days). Participants had a median age of 51 years (IQR: $34-63.5$ years) and $51 \%$ 
were female $(n=41)$ (Table 1). Most participants had mild $(n=47)$ or moderate $(n=29)$ COVID-19 illness, with one case of asymptomatic infection and four having severe disease.

\section{RBD endpoint titre and neutralising activity}

Assays to determine the endpoint titre (EPT) and neutralisation activity were performed at two timepoints ( $\mathrm{t} 1$ and $\mathrm{t} 2$ ) for all 81 participants. The RBD EPT was calculated from the dilution curve at the titration level equivalent to the optical density OD value equivalent to the mean plus two standard deviations from 20 healthy unexposed control participants. Neutralisation activity was determined with a MLV-based SARS-CoV-2 $\Delta 18$ pseudoparticle and a healthy control cut-off value of $34.19(10.82+2 \times 11.68)$, determined from the results of the same 20 healthy control participants.

At t1, 78 of 81 participants (96\%) had RBD EPTs greater than the limit of detection (Fig 1A). In addition, two of the three non-reactive participants did not have antibodies against the Spike protein (Fig S1A). For neutralisation activity, 45 of 81 participants $(56 \%)$ had an ID50 above cut-off (Fig 1B). At t2, the average ID50 and EPT values were significantly lower compared to t1 [mean difference (SEM) - ID50: 37.3 (14.0), $p=0.009$, EPT: 885 (258.4), $\mathrm{p}=0.001)$, but $95 \%(77 / 81)$ and $57 \%(46 / 81)$ of participants had EPT and neutralisation activity above the defined cut-offs (Fig S1B,C).

EPT and ID50 values at $\mathrm{t} 1$ were strongly predictive of values at $\mathrm{t} 2$ (ID50 $-\mathrm{r}^{2}=0.862$, $\left.\mathrm{p}<0.001, \mathrm{EPT}-\mathrm{r}^{2}=0.81, \mathrm{p}<0.001\right)$ (Fig 1C). EPT and ID50 results had a significant positive correlation at both time points $\left(\mathrm{t} 1: \mathrm{r}^{2}=0.55, \mathrm{p}<0.0001, \mathrm{t} 2: \mathrm{r}^{2}=0.38, \mathrm{p}=0.0006\right)$ (Fig $\mathrm{S} 1 \mathrm{D}, \mathrm{E})$. In unadjusted analysis, paired EPT values were associated with older age $(p=0.004)$ and the presence of diabetes mellitus, hypertension or obesity $(p=0.011)$ when the sampling interval was included as a covariate. Gender, illness severity, immunosuppression, and past or current history of smoking, were not associated with paired EPT values (Table S1). In the adjusted analysis (metabolic comorbidity vs. paired EPT measurements with sampling gap and age as covariates), the association with metabolic comorbidities disappeared while that for age and EPT was borderline $(p=0.05)$ (Table S2). Paired ID50 values did not have a significant association with any of the demographic or clinical variables assessed in the unadjusted analysis (Table S3). There were also no significant associations between demographic and clinical variables and fold-change in EPT or ID50 ( $\mathrm{t} 2$ value/t 1 value), except that a longer time between sample collection was associated with a greater fold decline of EPT and ID50 $(p<0.05)$.

\section{RBD-specific memory $B$ cells}

The observed decline in neutralising activity could be mitigated if a durable memory $B$ cell response capable of generating neutralising antibodies on demand is maintained. In order to assess the presence of a RBD-specific memory B cell response, 15 participants representing high $(>1000 \mathrm{EPT}, \mathrm{n}=5)$, medium $(\mathrm{EPT}: 100-999, \mathrm{n}=7)$ and low EPT $(\mathrm{EPT}<100, \mathrm{n}=3)$ at $\mathrm{t} 1$ were selected, and their $\mathrm{t} 1$ and $\mathrm{t} 2$ PBMCs were screened for RBDspecific CD27+ memory B cells by flow cytometry. The 15 participants were generally representative of the broader study cohort, in relation to gender (female $=7$ ), disease severity (mild $=4$, moderate $=7$, severe $=4$ ) and age (range 23 to 84 ). Six healthy uninfected participants were included as negative controls.

B cells were stained for flow cytometry and the CD19+CD20+CD10- population was analysed based on CD27, IgD, IgG and RBD binding phenotype (Fig S2A). Due to reports of lymphopenia in acute infection and concerns of skewed immune subsets, we first compared the $\mathrm{CD} 27+\mathrm{IgG}+\mathrm{RBD}+\mathrm{B}$ cell frequency calculated both as per million PBMCs 
and per million B cells (CD19+CD20+) and found a strong correlation. Hence, all further analyses were calculated as per million B cells only (Fig S2B).

As the focus of this study was on maintenance of virus-specific memory B cells, the analysis was performed on the CD27+RBD+ memory B cells and then sub-gated on IgD and IgG phenotype (Fig. 2A). The healthy participants had a high CD27+RBD+IgD+ frequency $\left(145.4 \pm 95.4 / 10^{6} \mathrm{~B}\right.$ cells), but low CD27+RBD+IgD-IgG $+\left(15.7 \pm 15.8 / 10^{6} \mathrm{~B}\right.$ cells) and CD27+RBD+IgD-IgG- frequencies $\left(20.3 \pm 17.9 / 10^{6} \mathrm{~B}\right.$ cells) (Fig 2B). The COSIN participants generally had higher mean frequencies of all three virus-specific subsets than the healthy participants: $C D 27+\mathrm{RBD}+\mathrm{IgD}+\left(265.6 \pm 314.2 / 10^{6} \mathrm{~B}\right.$ cells $)$, $\mathrm{CD} 27+\mathrm{RBD}+\operatorname{IgD}-\mathrm{IgG}+\left(251.3 \pm 254.8 / 10^{6} \mathrm{~B}\right.$ cells $)$ and CD27+RBD+IgD-IgG- $(52.3 \pm$ $72.7 / 10^{6} \mathrm{~B}$ cells) (Fig 2B). Despite some inter-subject variation, 12 out of 15 participants had a CD27+RBD+IgD-IgG+ frequency above the healthy control derived cut-off at 2 , and this was a significant increase from the same values observed at $\mathrm{t} 1$ (mean $\mathrm{t} 1=$ $165.8 / 10^{6} \mathrm{~B}$ cells; mean $\mathrm{t} 2=336.9 / 10^{6} \mathrm{~B}$ cells $\left.\mathrm{p}=0.0084\right)($ Fig $2 \mathrm{C})$. Two participants who did not have a CD27+RBD+IgD-IgG $+\mathrm{B}$ cell responses greater than the healthy cut-off were from the low EPT group, and had mild or moderate clinical illnesses; the third was from the high EPT group and had severe disease. There was overall a strong correlation between IgG EPT and CD27+RBD+IgD-IgG + B cell frequencies $(r=0.613$, pvalue $=0.017$ ) at 2 (Fig 2D). No correlation between ID50, gender, age or disease severity and $\mathrm{B}$ cell frequencies was observed (Fig S2E-G).

\section{RBD memory $B$ cells with neutralising capacity}

To investigate if these memory B cells were likely to have capacity to induce $\mathrm{NAb}$ responses upon reinfection, the B cell receptor from single cell sorted CD27+RBD+ cells from 5 participants were RT-PCR amplified and expressed as IgG1 monoclonal antibodies (mAbs) in Lenti-X 293T cells (Table 2). For this analysis, we selected three timepoints that had low to no detectable EPT and ID50 and three time points that had well above healthy cut-off titres. For participants that had a low $\mathrm{IgG}+$ cell frequency, IgD + cells were used (Table 2). A total of $76 \mathrm{mAbs}$ were successfully synthesised as IgG from $49 \mathrm{IgG}+$ cells and $27 \mathrm{IgD}+$ cells, as determined by an anti-IgG ELISA. Of the 49 mAbs made from IgG+ cells, 48 bound to RBD. From the IgD $+\mathrm{B}$ cells, two of the mAbs bound weakly to RBD. Antibody containing supernatant was also diluted 1 in 10 and screened for NAb activity with the SARS-2 pseudoparticle. A neutralisation percentage greater than 40 was defined as having neutralising activity. Of the $50 \mathrm{mAbs}$ that bound $\mathrm{RBD}, 14 \mathrm{mAbs}$ from three of the five participants had neutralising activity (Table 2) (Fig 2F). To further confirm the neutralising activity, the IC50 was determined for the two highest NAbs from each of the three participants by quantifying the mAbs in the cell culture supernatant and performing neutralisation assays on the SARS-CoV-2 pseudoparticles (Fig 2G). No neutralising antibodies were isolated from the two patients that did not seroconvert.

\section{Discussion}

Recent data on SARS-CoV-2 anti-RBD and anti-Spike antibody responses has suggested a significant and rapid decline in titres after resolution of the clinical illness. Our observation is that despite declining EPT and ID50 values at four to six months following infection, most individuals retain binding and neutralisation titres above background. Gender, disease severity, immunosuppression, comorbidities (diabetes mellitus, hypertension, obesity), and a past or current history of smoking, did not predict variation in ID50 or EPT over time. 
A decline in antibody titres and neutralising capacity following resolution of the clinical illness is not unusual, as seen in several other viral infections. However, the observation of antibody titres dipping below a detectable level is a concern for ongoing protection. Comparable declines in antibody titres would also be a significant concern following COVID-19 immunisation, if and when a vaccine is available ${ }^{17}$. Even though a potential vaccine against SARS-CoV-2 may not confer sterilising immunity (as this is rarely observed in other vaccines approved for use), the capacity of such a vaccine to minimise disease, reduce viral shedding and thence reduce transmission remains a highly desirable public health measure to control the pandemic.

The protective capacity of SARS-CoV-2 antibodies has recently been demonstrated in a candidate vaccine trial in rhesus macaques, in which seven different vaccines were administered to 32 macaques. The development of NAbs was associated with protection against lung infection and nasal infection in all but one of the macaques. ${ }^{18} \mathrm{In}$ another study, passive immunisation with a combination of NAbs in the monkeys correlated with reduced development of pneumonia and lung damage. ${ }^{19}$ These animal studies align with previous data on common coronaviruses, where reinfections (and presumed ongoing NAb activity) were often associated with very mild or asymptomatic disease ${ }^{10}$. The very few validated cases of reinfection of SARS-CoV-2 have also been associated with mild or asymptomatic infection. ${ }^{20}$

Encouragingly our data shows that despite the declining NAb titres, in the great majority of participants that seroconverted, memory B cells against RBD were maintained and even increased in numbers at four to six months following infection in 12 out of 13 participants. This finding was similar to three other studies that also reported the maintenance and expansion of the RBD-specific IgG memory repertoire ${ }^{16,17,21}$. These two studies followed participants up to five months post symptom onset. Our work extends beyond these studies both in time, but also shows for the first time that the memory B cell population can generate NAbs. How long these memory B cells continue to persist will be of significant interest. Tang et al. reported that the memory B cell responses to SARS$\mathrm{CoV}-1$ were undetectable at six years. However, it is worth noting that Tang et al. relied on ELISpot with pooled vaccine derived antigens to detect virus specific memory B cells, the standard assay at the time, whereas the common methods now use purified antigen and flow cytometry which are likely to be far more sensitive at detecting rare frequency events. ${ }^{22}$

Our study also identified a correlation between the frequency of RBD-specific memory B cells and RBD EPT, which indicates that RBD EPT may be a good and readily available marker for potential immunity. It is noteworthy, however, that the subject with the highest NAb titres had IgG RBD-specific memory B cells at background level only. Interestingly this participant had a severe illness with prominent lymphopenia reported during the acute phase of infection. Further work should be conducted among people with lymphopenia during acute SARS-CoV-2 infection to determine if the apparent loss of circulating lymphocytes, which are recognised to include both $\mathrm{T}$ and $\mathrm{B}$ cells, negatively impacts on the frequencies or quality of the memory cell response.

In summary, most participants diagnosed with SARS-CoV-2 infection who initially had an RBD specific immune response, had memory B cells persisting up to six months post infection with the capacity to make neutralising antibodies, despite falling NAb titres. The presence of memory B cells which produced NAbs following natural infection offers clear hope of protective immunity sufficient to reduce reinfection severity upon re- 
exposure, and promise for effective vaccine strategies based on NAb induction and for herd immunity.

\section{Methods}

Study design, setting and participants,

The COSIN (Collection of COVID-19 Outbreak Samples in NSW) study is an ongoing prospective cohort study evaluating the natural history of SARS-CoV-2 infection among adults and children in New South Wales, Australia. Children and adults diagnosed with SARS-CoV-2 infection (confirmed by NAT) were eligible for enrolment, irrespective of disease severity. Participants were enrolled through seven hospital in- and outpatient departments and referring microbiology laboratories in New South Wales between $6^{\text {th }}$ March 2020 and $17^{\text {th }}$ September 2020.

Follow up visits were scheduled at one month (visit window: one to three months) and four months (visit window: four to six months) following symptom onset or date of diagnosis (whichever was first). At each follow up visit, clinical data and blood samples were collected. Disease severity was classified according to the NIH stratification (www.covid19treatmentguidelines.nih.gov).

Healthy controls for antibody studies had a median age of 45 (range 24-73). Blood from 11 of the healthy controls were collected prior to 2007 and the remaining 9 were collected between March and April 2020 in Sydney, Australia, where local transmission was very low at the time. None of these 9 healthy controls had a history of COVID-19, were not close contacts of cases of COVID-19 and were not health care workers. For the memory B cell assays stored PBMCs from two of these healthy controls and stored PBMCs from four Australian Red Cross Lifeblood donors collected prior to 2020 were used (median age 38 , range 25 to 48 ).

\section{Ethics statement}

The protocol was approved by the Human Research Ethics Committees of the Northern Sydney Local Health District and the University of New South Wales, NSW Australia (ETH00520) and was conducted according to the Declaration of Helsinki and International Conference on $\mathrm{H}$ armonization Good Clinical Practice (ICH/GCP) guidelines and local regulatory requirements. Written informed consent was obtained from all participants before study procedures.

\section{$R B D$ and spike protein production}

SARS-CoV-2 Spike RBD (residues 319-541), with a N-terminal human Ig kappa leader sequence and C-terminal Avi- and His-tags, was cloned into pCEP4 (Invitrogen). Expi293-Freestyle cells (ThermoFisher Scientific) were cultured at $37^{\circ} \mathrm{C}$ and $8 \% \mathrm{CO}_{2}$ in growth medium containing Expi293 Expression Medium (ThermoFisher Scientific). The plasmid was transiently transfected into Expi293-Freestyle cells as follows: $1.5 \times 10^{8}$ total cells ( $50 \mathrm{~mL}$ transfection) were mixed with $50 \mu \mathrm{g}$ of plasmid, 160 $\mu \mathrm{L}$ of ExpiFectinamine and $6 \mathrm{~mL}$ of OptiMEM-I and left overnight at $37^{\circ} \mathrm{C}$ in a shaking incubator. The following day $300 \mu \mathrm{L}$ of ExpiFectamine Enhancer 1 and $3 \mathrm{~mL}$ of ExpiFectamine Enhancer 2 was added to the cells before the cells were left in culture for a further 48 hours. After a total of 72 hours in culture, the cell culture is collected and centrifuged for 20 minutes at $4000 \mathrm{xg}, 4^{\circ} \mathrm{C}$. Cellular debris was clarified by passing the supernatant twice through a $0.22 \mu \mathrm{M}$ filter. The His-tagged protein was then affinity purified from the cell supernatant using a HisTrap HP Column (GE Healthcare) and eluted with imidazole. The purified protein was then buffer exchanged and concentrated in sterile DPBS by centrifuging at $4000 \mathrm{xg}$ for 30 minutes at $4^{\circ} \mathrm{C}$ in a $10,000 \mathrm{MWCO}$ 
Vivaspin centrifugal concentrator (Sartorius) and stored at $-80^{\circ} \mathrm{C}$. The recombinant RBD was biotinylated using the Avitag as described by the manufacturer (Genecopeia).

\section{RBD binding and limit of detection}

Nunc-Immuno MicroWell plates, 96 well (ThermoFisher Scientific) were prepared with $250 \mathrm{ng}$ of recombinant SARS-2 RBD protein in DPBS and incubated overnight at $4{ }^{\circ} \mathrm{C}$. The plates were washed with PBS containing $0.05 \%$ Tween-20 (PBS-T) and blocked with $5 \%$ non-fat milk for an hour at room temperature (RT). Heat inactivated $\left(56^{\circ} \mathrm{C}\right.$ for 30 minutes) patient serum or monoclonal antibodies were 3 -fold serially diluted (1/20 to $1 / 1,180,980$ ) in 5\% non-fat milk, added to the plates in duplicate and incubated for two hours at RT. Anti-human IgG-HRP (Jackson Immunoresearch) was added at a 1:3000 dilution to the plates for one hour at room temperature. Binding of patient serum was detected using TMB Chromogen Solution (ThermoFisher Scientific) for 15 minutes at $\mathrm{RT}$ and the reaction was stopped using $1 \mathrm{M} \mathrm{HCl}$. Optical density (OD) at $450 \mathrm{~nm}$ was measured using CLARIOstar microplate reader (BMG Labtech). The background level in SARS-2 RBD was determined by adding $2 \mathrm{SD}$ to the mean $\mathrm{OD}_{450}$ of the highest dilution $(1 / 20)$ of sera from 20 healthy unexposed individuals.

\section{Anti-Spike antibody assay}

A flow cytometry live cell-based assay was used to detect patient serum SARS-COV-2 Spike IgG antibodies as previously performed for neuroimmunological assays ${ }^{23}$. Spike (Wuhan strain) was expressed on transfected HEK293 cells. Serum was added to live spike-expressing cells, followed by staining with Alexa Fluor 647-conjugated anti-human IgG $(\mathrm{H}+\mathrm{L})$ (ThermoFisher Scientific). Cells were acquired on the LSRII flow cytometer (BD Biosciences). Participants were determined Spike antibody-seropositive if their delta median fluorescence intensity $(\triangle \mathrm{MFI}=$ transfected cells MFI - untransfected cells MFI $)$ was above the positive threshold (mean $\Delta \mathrm{MFI}+4 \mathrm{SD}$ of 24 pre-pandemic controls) in at least two of three quality-controlled experiments. Data was analysed using FlowJo 10.4.1 (TreeStar).

\section{SARS-CoV-2 neutralisation}

All cells were cultured at $37^{\circ} \mathrm{C}$ and $5 \% \mathrm{CO}_{2}$ in growth medium containing high glucose Dulbecco's Modified Eagle Medium (ThermoFisher Scientific) supplemented with 10\% $\mathrm{v} / \mathrm{v}$ heat inactivated fetal bovine serum (Life Technologies; ThermoFisher Scientific). Retroviral SARS-CoV-2 pseudo-particles (SARS-2pp) were generated by co-transfecting expression plasmids containing SARS-CoV-2 Spike which were kindly provided by Dr Markus Hoffmann ${ }^{24}$, and the MLV gag/pol and luciferase vectors which were kindly provided by Prof. Francois-Loic Cosset ${ }^{25,26}$, in CD81KO 293T cells, which were kindly provided by Dr Joe Grove ${ }^{27}$, using mammalian Calphos transfection kit (Takara Bio). Culture supernatants containing SARS-2pp were harvested 48 hours post transfection and clarified of cellular debris by centrifugation at 500xg for 10 minutes. SARS-2pp were concentrated 10-fold using 100,000 MWCO Vivaspin centrifugal concentrators (Sartorius) by centrifugation at $2000 \mathrm{xg}$ and stored at $-80^{\circ} \mathrm{C}$.

For neutralisation assays, the infectivity of SARS-2pp were diluted in media to $1000-$ 5000 -fold more infectious than negative background (based on pseudoparticles lacking SARS-CoV-2 Spike). Diluted pseudoparticles were incubated for one hour with heat inactivated $\left(56^{\circ} \mathrm{C}\right.$ for 30 minutes $)$ patient serum or cell culture supernatant containing monoclonal antibodies, followed by the addition of polybrene at a final concentration of $4 \mu \mathrm{g} / \mathrm{mL}$ (Sigma-Aldrich), prior to addition to 293T-ACE2 over-expressed calls, which were kindly provided by A/Prof Jesse Bloom ${ }^{28}$. 293T-ACE2 cells were seeded 24 hours earlier at $1.5 \times 10^{4}$ cells per well in 96-well white flat bottom plates (Sigma-Aldrich). 
Cells were spinoculated at $800 \mathrm{xg}$ for two hours and incubated for two hours at $37^{\circ} \mathrm{C}$, prior to media change. After 72 hours, the cells were lysed with a lysis buffer (Promega) and Bright Glo reagent (Promega) was added at a 1:1 ratio. Luminescence (RLU) was measured using CLARIOstar microplate reader (BMG Labtech). Neutralisation assays were performed in triplicates and outliers were excluded using the modified $z$-score method $^{29}$. Percentage neutralisation of SARS-2pp was calculated as (1 $\left.\mathrm{RLU}_{\text {treatment }} / \mathrm{RLU}_{\text {no treatment }}\right) \times 100$. Serum neutralisation cut-off was determined using ID50 values obtained from 20 unexposed healthy participants (mean +2 SD). The neutralisation cutoff for the $\mathrm{mAb}$ containing cell culture media was determined as the mean $+2 \mathrm{SD}$ of the reading generated from screening neutralisation of the negative transfection control (no DNA). This was calculated to be $25.42 \%$ so any mAb with a neutralisation percentage greater than 40 at $1 / 10$ dilution was classified as having neutralising activity. The 50\% inhibitory concentration (ID50 for serum and IC50 for $\mathrm{mAbs}$ ) titre was calculated using non-linear regression model (GraphPad Prism).

\section{Staining RBD Memory B cells}

The tetramerization method was adapted from a previously published method used for hepatitis $C$ virus tetramers ${ }^{30}$. In brief, biotinylated RBD was incubated with StreptavidinPE (SA-PE; Molecular probes; ThermoFisher Scientific, ) in a molar ratio of 4:1 The streptavidin dye was added step-wise in $1 / 10^{\text {th }}$ volume increments to the biotinylated protein, for a total of 10 times with a 10 minute incubation at $4{ }^{\circ} \mathrm{C}$, in a rotating bioreactor, protected from light.

Cryopreserved PBMCs were thawed rapidly in a $37^{\circ} \mathrm{C}$ waterbath and washed with prewarmed RPMI media supplemented with $2 \mathrm{mML}$-glutamine, $50 \mathrm{IU} / \mathrm{mL}$ penicillin, $50 \mu \mathrm{g} / \mathrm{mL}$ streptomycin and 10\% heat inactivated fetal calf serum (Sigma). The cells were resuspended in DPBS and counted. All subsequent incubations were performed protected from light. A maximum of $1 \times 10^{7}$ cells were stained with Fixable Viability Stain 700 (FVS700) (BD Bioscience in a 1:1000 dilution) and incubated at $4^{\circ} \mathrm{C}$ for 20 minutes, to differentiate the live cells from dead. Cells were washed twice with FACS wash buffer (DPBS $+0.1 \%$ BSA), followed by incubation with $5 \mu \mathrm{L}$ Human Fc block (BD) per $2 \times$ $10^{6}$ cells at room temperature for 10 minutes, to block non-specific antibody binding. SARS-CoV-2-specific B cells were identified by staining with $1 \mu \mathrm{g} / \mathrm{mL}$ of RBD tetramer at $4^{\circ} \mathrm{C}$ for 30 minutes. All consecutive steps were done either at $4{ }^{\circ} \mathrm{C}$ or on ice and washed twice. The cocktail for staining contained $50 \mu \mathrm{L}$ stain brilliant buffer and the titrated combination of antibodies: $5 \mu \mathrm{L}$ each of CD21 BV421, IgD BV510, CD10 BV605, CD19 BV711 and CD20 APC-H7, $10 \mu \mathrm{L}$ of IgG BV786, $2 \mu \mathrm{L}$ each of CD27 PECF594 and CD38 PE-Cy7, 2.5 $\mu$ L HLA-DR BB515 and 0.5 $\mu$ L CD3 BB700. All the reagents were from $\mathrm{BD}$ Bioscience. The cells were incubated with the staining cocktail at $4^{\circ} \mathrm{C}$ for 30 minutes. They were washed and resuspended in FACS wash buffer. A BD FACSAria ${ }^{\mathrm{TM}}$ III sorter was used to phenotype and either bulk sort, or single cell sort, the samples. The data analysis was performed using FlowJo version 10.7.1 (TreeStar).

\section{Production of monoclonal antibodies from single-sorted RBD-specific B cells}

Natively paired heavy and light chain variable $\left(\mathrm{V}_{\mathrm{H}}\right.$ and $\left.\mathrm{V}_{\mathrm{L}}\right)$ region sequences were obtained by amplifying the regions separately from single sorted $\mathrm{B}$ cells as previously described $^{30}$. In brief, single sorted RBD-specific B cells $\left(\mathrm{CD} 19^{+} \mathrm{CD} 20^{+} \mathrm{CD} 10^{-} \mathrm{RBD}^{+}\right)$ were collected into 96-well PCR plates that contained in a final volume of $2 \mu \mathrm{L}$ per well: $0.5 \mu \mathrm{L}$ of dNTP $(10 \mathrm{mM})$ (ThermoFisher Scientific), $0.5 \mu \mathrm{l}$ of $5 \mu \mathrm{M}$ oligo-dT primer and $1 \mu \mathrm{L}$ of lysis buffer, lysis buffer was prepared by addition of $1 \mu \mathrm{L}$ (40 U) RNAse inhibitor (Clontech) to $19 \mu \mathrm{L}$ Triton X-10 $(0.2 \%[\mathrm{v} / \mathrm{v}])$. These samples were then RT-PCR amplified with the SmartSeq2 approach ${ }^{31}$. 
Amplicons of the $\mathrm{B}$ cell receptor (BCR)-encoding regions were generated from the SmartSeq2 libraries, as described previously ${ }^{30,32}$. Antibodies were generated by cotransfecting Lenti-X 293T cells (Clontech) with $1 \mu \mathrm{g}$ each of heavy and light chain expression cassette using $20 \mu \mathrm{L}$ of Polyfect Transfection Reagent (Qiagen) and $600 \mu \mathrm{L}$ of DMEM supplemented with $2 \mathrm{mM}$ L-glutamine, and $10 \%$ heat inactivated fetal calf serum (Sigma). Cells were incubated at $37^{\circ} \mathrm{C}$ and $5 \% \mathrm{CO}_{2}$ for $6-8$ hours before media was replaced with $3 \mathrm{~mL}$ of DMEM supplemented with $2 \%$ heat inactivated fetal calf serum and $1 \%$ penicillin/streptomycin, and incubated under the same conditions for a further 67-72 hours. Media was then collected and centrifuged to isolate supernatant containing antibodies, before storage at $-20^{\circ} \mathrm{C}$.

A RBD binding ELISA was performed on the undiluted mAbs, as described above for serum, to determine the specificity of the RBD tetramer-sorted memory B cells. Successful transfection and mAb synthesis was confirmed with a total IgG ELISA. In brief, Nunc-Immuno MicroWell plates, 96 well (Thermo Scientific,) were prepared with $1 \mu \mathrm{g}$ of anti-human IgG (Jackson Immunoresearch) in DPBS and incubated for one hour at $37^{\circ} \mathrm{C}$. The plates were washed with TBS containing $0.05 \%$ Tween-20 (TBS-T) and blocked with 5\% non-fat milk for an hour at RT. The mAbs were added to the plates in duplicates and incubated for one hour at RT. Anti-human IgG-HRP (Jackson Immunoresearch) was added at a 1:6000 dilution to the plates for one hour at RT. Binding of mAbs was detected using TMB Chromogen Solution (ThermoFisher Scientific) for 15 minutes at room temperature and the reaction was stopped using $1 \mathrm{M} \mathrm{HCl}$. Optical density (OD) at $450 \mathrm{~nm}$ was measured using CLARIOstar microplate reader (BMG Labtech).

\section{Statistical analyses}

The EPT and ID50 analyses were performed in GraphPad Prism 8.4.3. Wilcoxon or Mann-Whitney tests were applied for paired and unpaired analyses, respectively, to evaluate statistically significant differences between $\mathrm{t} 1$ and $\mathrm{t} 2$. EPT and ID50 values were fitted to a Loess curve using ggplot2 package in R 4.0.2 using stat_smooth() function with default parameters. Correlation analyses were performed using the non-parametric Spearman's test. ID50 and Spike binding data were plotted using a linear scale. EPT data were plotted using a log transformed scale. Statistical significance was set at $p<0.05$.

Descriptive statistics are given as count data (for discrete variables) or as measures of central tendency and dispersion (for continuous data). ID50 and EPT were measured at two time points per subject ( $\mathrm{t} 1: 1-3$ months post infection, $\mathrm{t} 2: 4-6$ months post infection) and their distributions were compared with a paired sample t-test. Associations for variation of ID50 and EPT (dependent variables) were explored with a mixed model analysis for within (time) and between host effects, while considering time gap between sampling points as a covariate (using repeated measures ANOVA). In the unadjusted analysis, each of the following independent (between-host) variables were compared: gender (male vs. female), disease severity (asymptomatic or mild vs. moderate or severe), immunosuppression, age, current or past history of smoking, metabolic comorbidities (either diabetes, hypertension or obesity). If any significant associations were noted, they were combined in an adjusted analysis (repeated measures ANOVA). Statistical significance was set at $\mathrm{p}<0.05$.

In addition, associations were also explored for the fold decline of EPT and ID50 (dependent variable) across the two time points (e.g. ID50t2/ID50t1) with the same independent variables as above, using univariate analysis of variance. To remove extreme values of fold-change, the outlier participants were removed by only considering those within the interquartile range (Q1-Q3) for EPT and ID50 data arrays at the first time point. For the memory B cell evaluation, statistical analysis was performed on log transferred data values. The number of CD27+ IgG $+\mathrm{RBD}+$ cells $/ 10^{6} \mathrm{~B}$ cells were measured the two timepoints and their distributions was compared with a Wilcoxon matched-pairs 
signed rank test. A simple linear regression model was used to analyse the relationship between the memory B cell numbers and the age, ID50 and EPT at individual timepoints of each participant. A Mann Whitney test was performed to compare the inter/intragender and disease severity association with the RBD MBC numbers. A non-parametric Spearman's test was performed for correlation analysis.

\section{Acknowledgements}

The authors would like to thank the study participants for their contribution to the research, as well as current and past researchers and staff. They would like to acknowledge members of the study group: Protocol Steering Committee - Rowena Bull (Co-Chair, The Kirby Institute, UNSW Sydney, Sydney, Australia), Marianne Martinello (Co-Chair, The Kirby Institute, UNSW Sydney, Sydney, Australia), Andrew Lloyd (The Kirby Institute, UNSW Sydney, Sydney, Australia), John Kaldor (The Kirby Institute, UNSW Sydney, Sydney, Australia), Greg Dore (The Kirby Institute, UNSW Sydney, Sydney, Australia), Tania Sorrell (Marie Bashir Institute, University of Sydney, Sydney, Australia), William Rawlinson (NSWHP), Jeffrey Post (POWH), Bernard Hudson (RNSH), Dominic Dwyer (NSWHP), Adam Bartlett (SCH), Sarah Sasson (UNSW) and Daniel Lemberg (SCHN). Coordinating Centre - The Kirby Institute, UNSW Sydney, Sydney, Australia - Rowena Bull (Co-ordinating principal investigator), Marianne Martinello (Co-ordinating principal investigator), Marianne Byrne (Clinical Trials Manager), Mohammed Hammoud (Post-Doctoral Fellow and Data Manager), Andrew Lloyd (Investigator) and Roshana Sultan (Study co-ordinator).

Site Principal Investigators - Jeffrey Post (Prince of Wales Hospital, Sydney, Australia), Michael Mina (Northern Beaches, Sydney, Australia), Bernard Hudson (Royal North Shore Hospital, Sydney, Australia), Nicky Gilroy (Westmead Hospital, Sydney, Australia), William Rawlinson (New South Wales Health Pathology, NSW, Australia), Pam Konecny (St George Hospital, Sydney, Australia), Marianne Martinello (Blacktown Hospital), Adam Bartlett (Sydney Children's Hospital, Sydney, Australia) and Gail Matthews (St Vincent's Hospital, Sydney, Australia). Site co-ordinators - Dmitrii Shek and Susan Holdaway (Blacktown hospital), Katerina Mitsakos (RNSH), Dianne How-Chow and Renier Lagunday (POWH), Sharon Robinson (SGH), Lenae Terrill (NBH), Neela Joshi, (Lucy) Ying Li and Satinder Gill (Westmead), Alison Sevehon (SVH).

\section{Funding}

The Kirby Institute is funded by the Australian Government Department of Health and Ageing. The views expressed in this publication do not necessarily represent the position of the Australian Government. Research reported in this publication was supported by Snow Medical Foundation as an investigator-initiated study. The content is solely the responsibility of the authors. RAB, MM, CR and ARL are fellows funded by National Health and Medical Research Council (NHMRC). 
Table 1. Characteristics of COSIN participants $(n=81)$

\begin{tabular}{lcccc}
\hline & $\begin{array}{c}\text { Total study } \\
\text { population, } \\
\text { n (\%) }\end{array}$ & $\begin{array}{c}\text { Asymptomatic } \\
\text { or mild, } \\
\mathbf{n}(\%)\end{array}$ & $\begin{array}{c}\text { Moderate, } \\
\text { n (\%) }\end{array}$ & $\begin{array}{c}\text { Severe, } \\
\text { n (\%) }\end{array}$ \\
\hline Age, median (range) & $52(19-84)$ & $54(20-82)$ & $47(19-76)$ & $72(23-84)$ \\
\hline Age, by category, n (\%) & & & & \\
$<40$ & $27(33)$ & $14(29)$ & $12(41)$ & $1(25)$ \\
$40-59$ & $24(30)$ & $16(33)$ & $8(28)$ & $0(0)$ \\
$>60$ & $30(37)$ & $18(38)$ & $9(31)$ & $3(75)$ \\
\hline Sex, n (\%) & & & & \\
Female & $41(51)$ & $25(52)$ & $15(52)$ & $1(25)$ \\
Male & $40(49)$ & $23(43)$ & $14(48)$ & $3(75)$ \\
\hline Disease severity, n (\%) & & & & NA \\
Asymptomatic or mild & $48(59)$ & $48(100)$ & $29(100)$ & NA \\
Moderate & $29(26)$ & NA & NA & $4(100)$ \\
Severe & $4(5)$ & NA & &
\end{tabular}

5

6

7

8

Table 2. Monoclonal antibodies and their reactivity to RBD by subject

\begin{tabular}{l|cc|cccc}
\hline \multirow{2}{*}{ Subject ID } & \multicolumn{2}{|c|}{ Plasma characteristics } & \multicolumn{4}{c}{ mAb charactersitics } \\
\cline { 2 - 6 } & DPS & RBD titre & $\begin{array}{c}\text { IgG } \\
\text { derived }\end{array}$ & $\begin{array}{c}\text { IgD } \\
\text { derived }\end{array}$ & $\begin{array}{c}\text { RBD } \\
\text { binding }\end{array}$ & Neutralising \\
\hline $61250-011$ & 68 & 1857.63 & 4 & 0 & 4 & 1 \\
& 181 & 491.67 & 20 & 0 & 20 & 5 \\
$61213-007$ & 132 & 0 & 15 & 0 & 15 & 6 \\
$61250-002$ & 110 & 493.95 & 9 & 0 & 9 & 2 \\
$61213-016$ & 137 & 12.24 & 1 & 12 & 2 & 0 \\
$61247-024$ & 118 & 0 & 0 & 15 & 0 & 0 \\
\hline
\end{tabular}


A

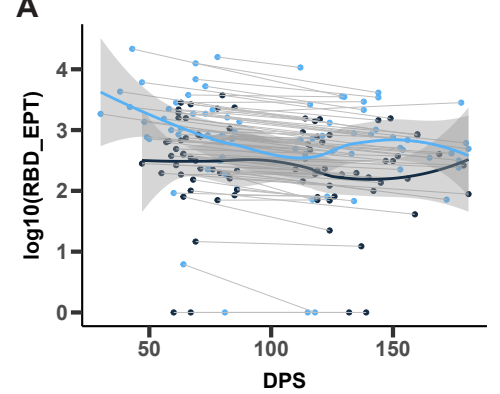

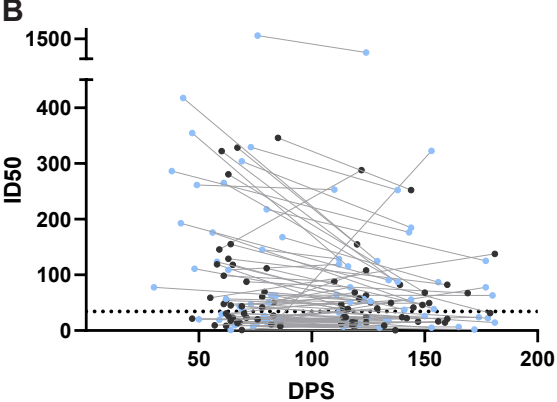

C

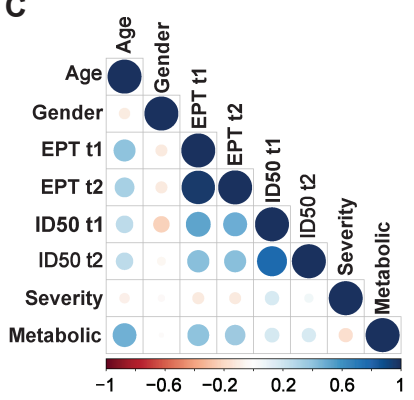

2

3

4

5

6

8

9

10

11

12

13

Fig 1: Antibody analysis (A) RBD endpoint titres (EPT) plotted against days post onset of symptoms (DPS). The curve shows the mean EPT values using a Loess regression model. The shaded band indicates the $95 \%$ confidence interval. Blue datapoints highlight participants $>51$ years (median age) and black datapoints highlight participants $<51$ years. (B) ID50 values plotted against the DPS. The lines connect a single subject sampled at two time points. The healthy control cut-off (mean $+2 \times \mathrm{SD}$ ) is indicated by the dotted black line. Blue datapoints highlight participants $>51$ years (median age) and black datapoints highlight participants $<51$ years. (C) Correlogram comparing RBD EPT and ID50 values at both timepoints with age, gender, disease severity and metabolic comorbidities. Correlations were performed with the Spearman correlation statistic. 
A

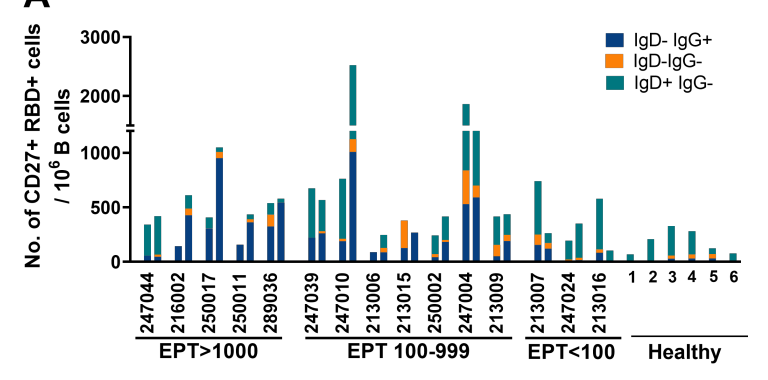

C

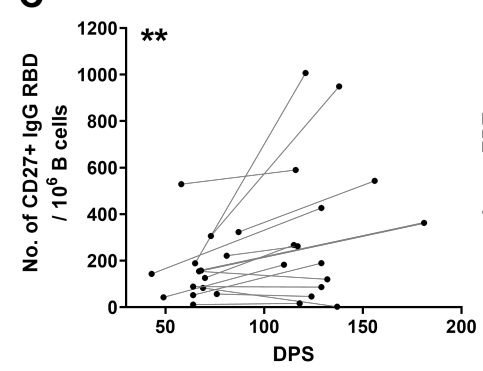

F

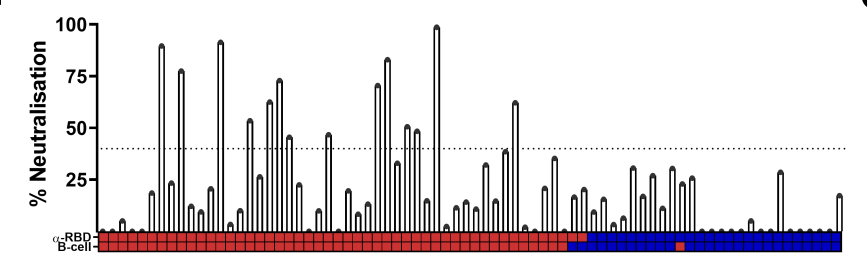

D

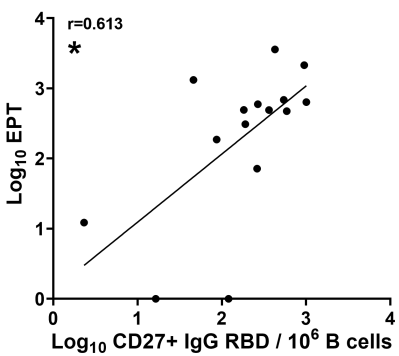

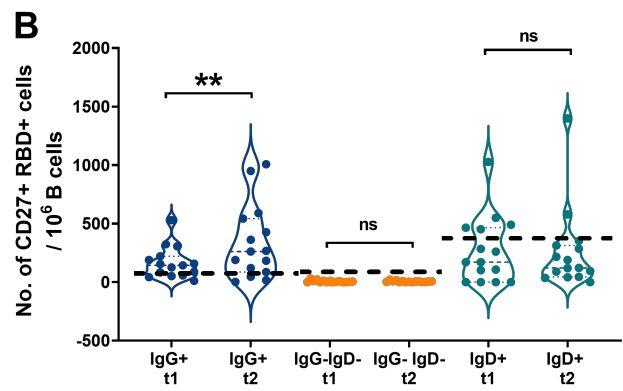

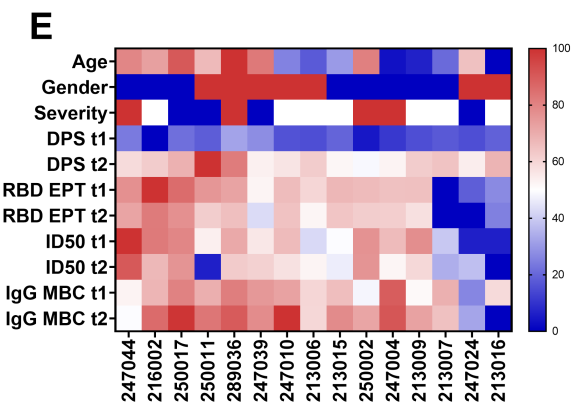

G

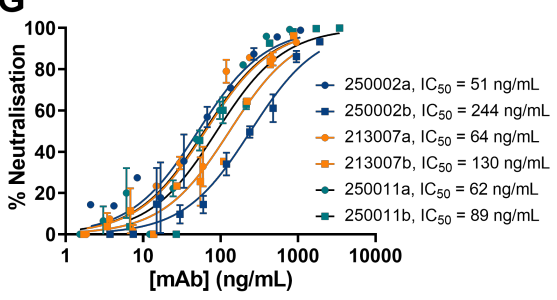

Fig 2: Memory B cell analysis and monoclonal antibody characteristics (A) Distribution of RBD specific Ig classes $/ 10^{6} \mathrm{~B}$ cells across all the EPT groups. The first bar represents $\mathrm{t} 1$ and the second bar represents 2 of each SARS-CoV-2 participant. Healthy participants have one bar representing one timepoint. (B) Violin plots of Ig subclass comparison between $\mathrm{t} 1$ and $\mathrm{t} 2$. Healthy control cutoff (mean $+2 \times S D$ ) are represented by the dotted black line. (C) Comparison of CD27+lgG+RBD+ $B$ cells $/ 10^{6} B$ cells between $t 1$ and $t 2$ showing an increase in frequencies (Wilcoxon matched-pairs signed rank test $p=0.0084$ ). (D) Correlation analysis between EPT and $\mathrm{CD} 27+\lg \mathrm{G}+\mathrm{RBD}+\mathrm{B}$ cells $/ 10^{6} \mathrm{~B}$ cells during t2 (spearman's correlation, $p=0.017$ ). (E) Heat map of all subjects comparing age, gender, severity, DPS, EPT, ID50, CD27+IgG+RBD+ B cells $/ 10^{6} \mathrm{~B}$ cells from $\mathrm{t} 1$ and $\mathrm{t} 2$. $(\mathrm{F})$ Neutralisation activity of all mAbs at $1 / 10$ dilution. Dotted line represents $40 \%$ neutralisation cut-off. Heat map shows mAb RBD binding (red above and blue below cutoff) and IgG line shows whether the originating memory B cell was $\lg G+($ red) or lgD+ (blue). (G) Neutralisation plot of six mAbs identified from three SARS-CoV-2 participants at t2, each colour represents a participant. 
A

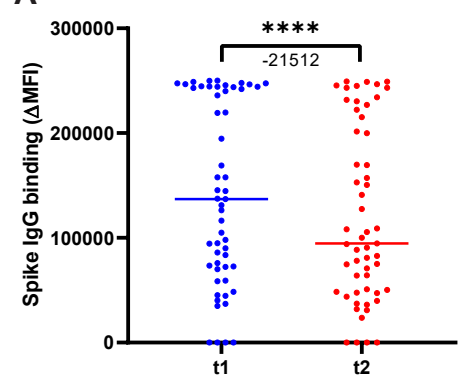

D

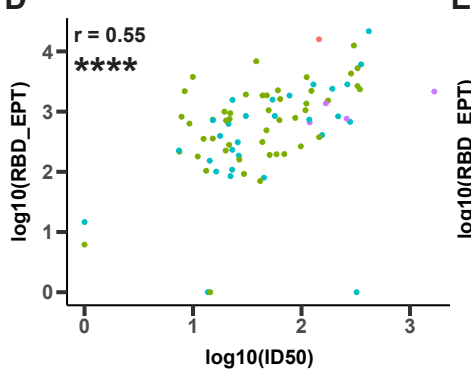

B

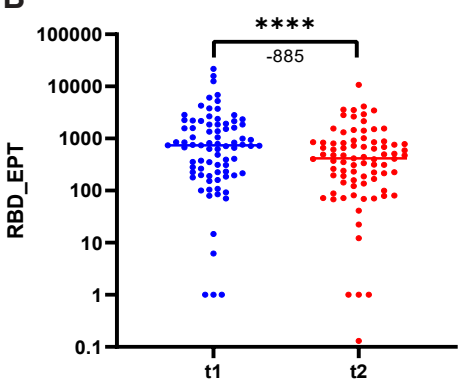

E

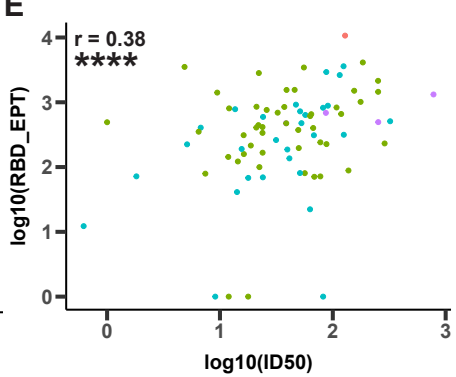

C

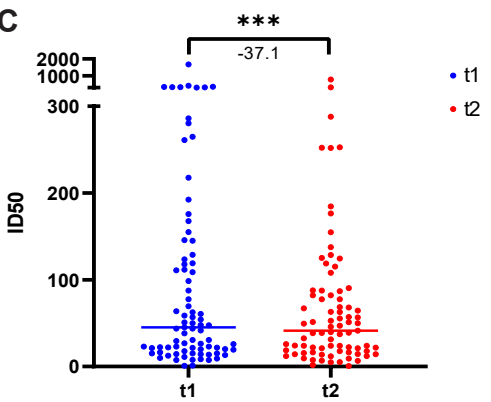

$\mathbf{F}$

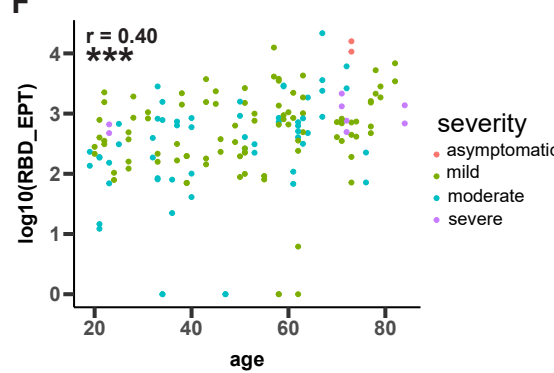

Supp fig 1: Plot showing significant decrease in IgG antibodies against Spike (A) and RBD (B) between $\mathrm{t} 1$ and $\mathrm{t} 2$. (C) ID50 values significantly lower at t2 compared to t1. Spearman's correlation of RBD EPT and ID50 at t1 (D) and t2 (E). Plot showing a significant correlation between age and RBD EPT (Spearman's correlation, $p<0.001$ ). 

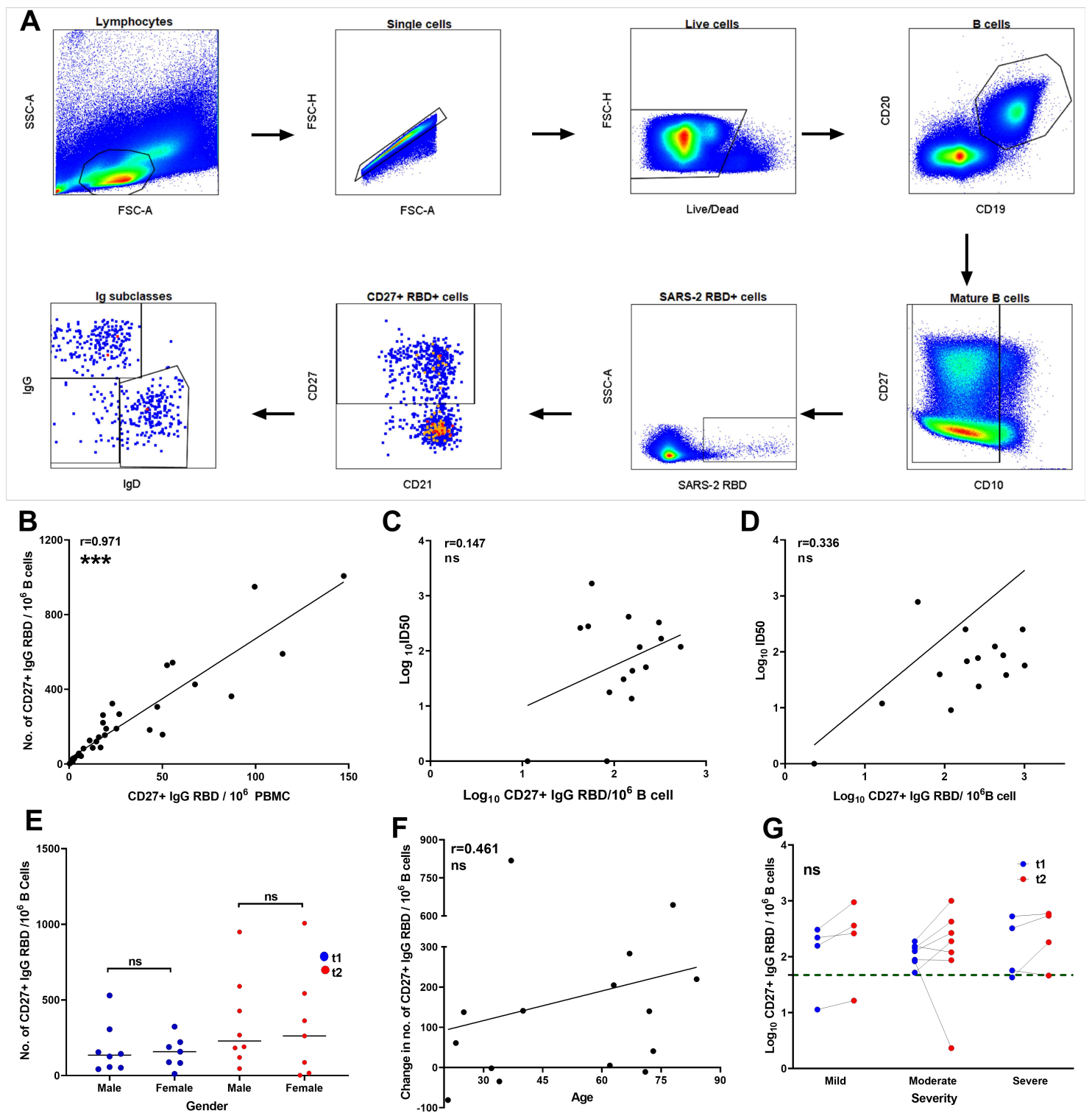

Supp fig 2: (A) Gating strategy for flow cytometry analysis of RBD-specific B cells. (B) Correlation of $C D 27+\lg G+R B D+B$ cells $/ 10^{6} P B M C$ with $C D 27+\lg G+R B D+B$ cells $/ 10^{6} B$ cells (Spearman's correlation, $p<0.001$ ). (C, D) Plots showing no correlation between ID50 and $\mathrm{CD} 27+\lg G+\mathrm{RBD}+\mathrm{B}$ cells $/ 10^{6} \mathrm{~B}$ cells at $\mathrm{t} 1$ and $\mathrm{t} 2$ (Spearman's correlation, not significant (ns)). (E) Comparison of CD27+lgG+RBD+ cells / $10^{6} \mathrm{~B}$ cells between genders. No significance (Mann Whitney test). (F) Change in number of CD27+lgG+RBD+ cells / $10^{6} \mathrm{~B}$ cells from t1 to t2 plotted against age of subjects. No correlation was observed (Spearman's correlation (twotailed) $p=0.086$ ). (G) Plot of disease severity against $C D 27+\lg G+R B D+$ cells $/ 10^{6} B$ cells from t1 to t2. Value for healthy control subjects (mean $+2 \times S D$ ) in green dotted line. 
1 Supplementary tables - Statistics

2 Table S1. Associations of clinical and demographic variables with RBD endpoint titres (EPT)

3 at first and second timepoints assessed with repeated measures ANOVA* $(n=81$, each subject

4 has two EPT measurements)

\begin{tabular}{|c|c|c|c|c|}
\hline Variable & Frequency & $\begin{array}{l}\text { Mean EPT } \\
\text { at t1 }\end{array}$ & $\begin{array}{l}\text { Mean EPT } \\
\quad \text { at t } 2\end{array}$ & $\begin{array}{l}\text { P value for } \\
\text { between- } \\
\text { subjects } \\
\text { effect }\end{array}$ \\
\hline $\begin{array}{l}\text { Gender } \\
\text { Male } \\
\text { Female }\end{array}$ & $\begin{array}{l}40 \\
41\end{array}$ & $\begin{array}{l}2111.0 \\
1371.9\end{array}$ & $\begin{array}{r}1038.8 \\
669.6\end{array}$ & 0.286 \\
\hline $\begin{array}{l}\text { Age } \\
\text { Above median (51 years) } \\
\text { Below median (51 years) }\end{array}$ & $\begin{array}{l}40 \\
41 \\
\end{array}$ & $\begin{array}{r}2728.8 \\
769.1 \\
\end{array}$ & $\begin{array}{r}1277.2 \\
437.0 \\
\end{array}$ & $0.005^{* * *}$ \\
\hline $\begin{array}{l}\text { Disease severity } \\
\text { Asymptomatic or mild } \\
\text { Moderate or severe }\end{array}$ & $\begin{array}{l}48 \\
33 \\
\end{array}$ & $\begin{array}{l}1820.1 \\
1615.7 \\
\end{array}$ & $\begin{array}{r}1002.7 \\
632.6 \\
\end{array}$ & 0.579 \\
\hline $\begin{array}{l}\text { Current or past history of } \\
\text { smoking } \\
\text { Yes } \\
\text { No }\end{array}$ & $\begin{array}{l}40 \\
41 \\
\end{array}$ & $\begin{array}{l}2350.1 \\
1138.6 \\
\end{array}$ & $\begin{array}{r}1037.8 \\
670.5 \\
\end{array}$ & 0.119 \\
\hline $\begin{array}{l}\text { Risk of immunosuppression }{ }^{* *} \\
\text { Yes } \\
\text { No }\end{array}$ & $\begin{array}{l}12 \\
69 \\
\end{array}$ & $\begin{array}{l}2462.7 \\
1610.6\end{array}$ & $\begin{array}{r}1674.0 \\
708.9 \\
\end{array}$ & 0.209 \\
\hline $\begin{array}{l}\text { Metabolic comorbidity } \\
\text { Yes } \\
\text { No }\end{array}$ & $\begin{array}{l}26 \\
55\end{array}$ & $\begin{array}{l}2853.6 \\
1208.9\end{array}$ & $\begin{array}{r}1504.1 \\
543.6\end{array}$ & $0.013^{* * *}$ \\
\hline
\end{tabular}

5 *all analyses per variable had sampling gap between $\mathrm{t} 1$ and $\mathrm{t} 2$ as a covariate which was not 6 significant in the final result, **includes individuals with diabetes mellitus, cancer, long term 7 immunosuppressants, chronic kidney disease (excludes those on short courses of

8 oral/intravenous steroids and inhaled steroids), ${ }^{* * *} \mathrm{p}<0.05,{ }^{*}$ Individuals with either diabetes,

9 hypertension, obesity or a combination of these 
1 Table S2. Adjusted analysis for EPT using repeated measures ANOVA (independent variable 2 metabolic comorbidity, covariates - age and sampling gap)

3

\begin{tabular}{lccccr}
\hline Source & $\begin{array}{c}\text { Type III Sum of } \\
\text { Squares }\end{array}$ & df & Mean Square & F & Sig. \\
\hline Intercept & 1364363.882 & 1 & 1364363.882 & 0.143 & 0.706 \\
Sampling gap & 4659499.379 & 1 & 4659499.379 & 0.489 & 0.487 \\
Age & 37670821.87 & 1 & 37670821.87 & 3.953 & 0.050 \\
Metabolic comorbidity & 16938553.89 & 1 & 16938553.89 & 1.777 & 0.186 \\
Error & 733786894.7 & 77 & 9529699.931 & & \\
\hline
\end{tabular}

4

5

6 
1 Table S3. Associations of clinical and demographic variables with ID50 at first and second 2 timepoints assessed with repeated measures ANOVA* $(n=81$, each subject has two ID50

3 measurements)

\begin{tabular}{|c|c|c|c|c|}
\hline Variable & Frequency & $\begin{array}{l}\text { Mean ID50 } \\
\text { at t1 }\end{array}$ & $\begin{array}{l}\text { Mean ID50 } \\
\text { at t2 }\end{array}$ & $\begin{array}{c}\text { P value for } \\
\text { between- } \\
\text { subjects } \\
\text { effect }\end{array}$ \\
\hline \multicolumn{5}{|l|}{ Gender } \\
\hline Male & 40 & 138.3 & 77.8 & 0.320 \\
\hline Female & 41 & 82.3 & 67.7 & \\
\hline \multicolumn{5}{|l|}{ Age } \\
\hline Above median (51 years) & 40 & 146.2 & 91.3 & 0.101 \\
\hline Below median (51 years) & 41 & 74.6 & 54.5 & \\
\hline \multicolumn{5}{|l|}{ Disease severity } \\
\hline Asymptomatic or mild & 48 & 77.4 & 63.9 & 0.137 \\
\hline Moderate or severe & 33 & 157.3 & 85.6 & \\
\hline \multicolumn{5}{|l|}{$\begin{array}{l}\text { Current or past history of } \\
\text { smoking }\end{array}$} \\
\hline Yes & 40 & 120.7 & 79.4 & 0.616 \\
\hline No & 41 & 99.6 & 66.2 & \\
\hline \multicolumn{5}{|c|}{ Risk of immunosuppression** } \\
\hline Yes & 12 & 91.1 & 74.5 & 0.834 \\
\hline No & 69 & 113.2 & 72.4 & \\
\hline \multicolumn{5}{|l|}{ Metabolic comorbidity $^{\#}$} \\
\hline Yes & 26 & 112.7 & 73.8 & 0.909 \\
\hline No & 55 & 108.7 & 72.2 & \\
\hline
\end{tabular}

*all analyses per variable had sampling gap between $\mathrm{t} 1$ and $\mathrm{t} 2$ as a covariate which was not 5 significant in the final result, **includes individuals with diabetes mellitus, cancer, long term 6 immunosuppressants, chronic kidney disease (excludes those on short courses of

7 oral/intravenous steroids and inhaled steroids), ${ }^{\#}$ Individuals with either diabetes, hypertension, 8 obesity or a combination of these

9

10

11

12 


\section{References}

1 Lucas, M., Karrer, U., Lucas, A. \& Klenerman, P. Viral escape mechanisms-escapology taught by viruses. Int J Exp Pathol 82, 269-286 (2001).

2 Huang, C. et al. Clinical features of patients infected with 2019 novel coronavirus in Wuhan, China. Lancet 395, 497-506 (2020).

3 Jiang, M. et al. T-cell subset counts in peripheral blood can be used as discriminatory biomarkers for diagnosis and severity prediction of Coronavirus disease 2019. J Infect Dis 222, 198-202, doi:10.1016/j.bcmd.2020.102437 (2020).

4 Stringhini, S. et al. Seroprevalence of anti-SARS-CoV-2 IgG antibodies in Geneva, Switzerland (SEROCoV-POP): a population-based study. Lancet, doi:10.1001/jama.2020.8279 (2020).

5 Seow, J. et al. Longitudinal evaluation and decline of antibody responses in SARSCoV-2 infection. medRxiv (2020).

6 Long, Q. X. et al. Antibody responses to SARS-CoV-2 in patients with COVID-19. Nat Med 26, 845-848, doi:10.1038/s41591-020-0897-1 (2020).

7 Rydyznski Moderbacher, C. et al. Antigen-Specific Adaptive Immunity to SARSCoV-2 in Acute COVID-19 and Associations with Age and Disease Severity. Cell, doi:https://doi.org/10.1016/i.cell.2020.09.038 (2020).

8 Funk, C. D., Laferriere, C. \& Ardakani, A. A Snapshot of the Global Race for Vaccines Targeting SARS-CoV-2 and the COVID-19 Pandemic. Front Pharmacol 11, 937, doi:10.3389/fphar.2020.00937 (2020).

9 Giménez, E. et al. SARS-CoV-2-reactive interferon- $\gamma$-producing CD8+ T cells in patients hospitalized with coronavirus disease 2019. J Med Virol, doi:10.1101/2020.06.08.13882610.1002/jmv.26213 (2020).

10 Vabret, N. et al. Immunology of COVID-19: current state of the science. Immunity 52, 910-941 (2020).

11 Thevarajan, I. et al. Breadth of concomitant immune responses prior to patient recovery: a case report of non-severe COVID-19. Nat Med 26, 453-455 (2020).

12 Huang, A. T. et al. A systematic review of antibody mediated immunity to coronaviruses: antibody kinetics, correlates of protection, and association of antibody responses with severity of disease. medRxiv (2020).

13 Gudbjartsson, D. F. et al. Spread of SARS-CoV-2 in the Icelandic Population. $N$ Engl J Med 382, 2302-2315, doi:10.1056/NEJMoa2006100 (2020).

14 Ladhani, S. N. et al. High prevalence of SARS-CoV-2 antibodies in care homes affected by COVID-19; a prospective cohort study in England. medRxiv (2020).

15 Cao, W. C., Liu, W., Zhang, P. H., Zhang, F. \& Richardus, J. H. Disappearance of antibodies to SARS-associated coronavirus after recovery. $N$ Engl J Med 357, 11621163, doi:10.1056/NEJMc070348 (2007).

16 Vaisman-Mentesh, A. et al. SARS-CoV-2 specific memory B cells frequency in recovered patient remains stable while antibodies decay over time. medRxiv (2020).

17 Wheatley, A. K. et al. Evolution of immunity to SARS-CoV-2. medRxiv, 2020.2009.2009.20191205, doi:10.1101/2020.09.09.20191205 (2020).

18 Mercado, N. B. et al. Single-shot Ad26 vaccine protects against SARS-CoV-2 in rhesus macaques. Nature, doi:10.1038/s41586-020-2607-z (2020).

19 Baum, A. et al. REGN-COV2 antibody cocktail prevents and treats SARS-CoV-2 infection in rhesus macaques and hamsters. bioRxiv (2020).

20 Gupta, V. et al. Asymptomatic reinfection in two healthcare workers from India with genetically distinct SARS-CoV-2. Clin Infect Dis, doi:10.1093/cid/ciaa1451 (2020).

21 Rodda, L. B. et al. Functional SARS-CoV-2-specific immune memory persists after mild COVID-19. medRxiv (2020). 
22 Tang, F. et al. Lack of peripheral memory B cell responses in recovered patients with severe acute respiratory syndrome: a six-year follow-up study. J Immunol 186, 7264-7268, doi:10.4049/jimmunol.0903490 (2011).

23 Tea, F. et al. Characterization of the human myelin oligodendrocyte glycoprotein antibody response in demyelination. Acta Neuropathol Commun 7, 145, doi:10.1186/s40478-019-0786-3 (2019).

24 Hoffmann, M., Kleine-Weber, H. \& Pohlmann, S. A Multibasic Cleavage Site in the Spike Protein of SARS-CoV-2 Is Essential for Infection of Human Lung Cells. Mol Cell 78, 779-784 e775, doi:10.1016/j.molcel.2020.04.022 (2020).

25 Keck, Z. Y. et al. Mutations in hepatitis C virus E2 located outside the CD81 binding sites lead to escape from broadly neutralizing antibodies but compromise virus infectivity. J Virol 83, 6149-6160, doi:10.1128/JVI.00248-09 (2009).

26 Bartosch, B. et al. In vitro assay for neutralizing antibody to hepatitis $\mathrm{C}$ virus: evidence for broadly conserved neutralization epitopes. Proc Natl Acad Sci U S A 100, 14199-14204, doi:10.1073/pnas.2335981100 (2003).

27 Kalemera, M. D. et al. Optimised cell systems for the investigation of hepatitis C virus E1E2 glycoproteins. bioRxiv, 2020.2006.2018.159442, doi:10.1101/2020.06.18.159442 (2020).

28 Crawford, K. H. D. et al. Protocol and Reagents for Pseudotyping Lentiviral Particles with SARS-CoV-2 Spike Protein for Neutralization Assays. Viruses 12, doi:10.3390/v12050513 (2020).

29 Hoaglin, D. C. Revising a display of multidimensional laboratory measurements to improve accuracy of perception. Methods Inf Med 32, 418-420 (1993).

$30 \mathrm{Wu}, \mathrm{B}$. R. et al. A method for detecting hepatitis $\mathrm{C}$ envelope specific memory B cells from multiple genotypes using cocktail E2 tetramers. J Immunol Methods 472, 6574, doi:10.1016/j.jim.2019.06.016 (2019).

31 Rizzetto, S. et al. B-cell receptor reconstruction from single-cell RNA-seq with VDJPuzzle. Bioinformatics 34, 2846-2847, doi:10.1093/bioinformatics/bty203 (2018).

32 Liao, H. X. et al. High-throughput isolation of immunoglobulin genes from single human B cells and expression as monoclonal antibodies. J Virol Methods 158, 171179, doi:10.1016/j.jviromet.2009.02.014 (2009). 


\section{Figures}
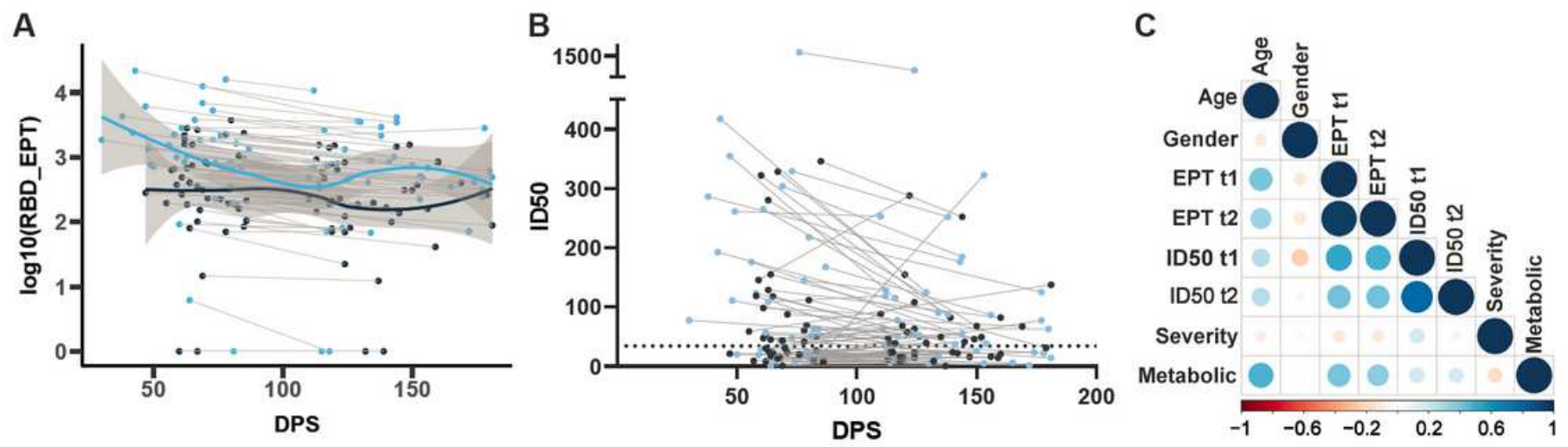

\section{Figure 1}

Antibody analysis (A) RBD endpoint titres (EPT) plotted against days post onset of symptoms (DPS). The curve shows the mean EPT values using a Loess regression model. The shaded band indicates the $95 \%$ confidence interval. Blue datapoints highlight participants $>51$ years (median age) and black datapoints highlight participants $<51$ years. (B) ID50 values plotted against the DPS. The lines connect a single subject sampled at two time points. The healthy control cut-off (mean $+2 \times \mathrm{SD})$ is indicated by the dotted black line. Blue datapoints highlight participants $>51$ years (median age) and black datapoints highlight participants $<51$ years. (C) Correlogram comparing RBD EPT and ID50 values at both timepoints with age, gender, disease severity and metabolic comorbidities. Correlations were performed with the Spearman correlation statistic. 

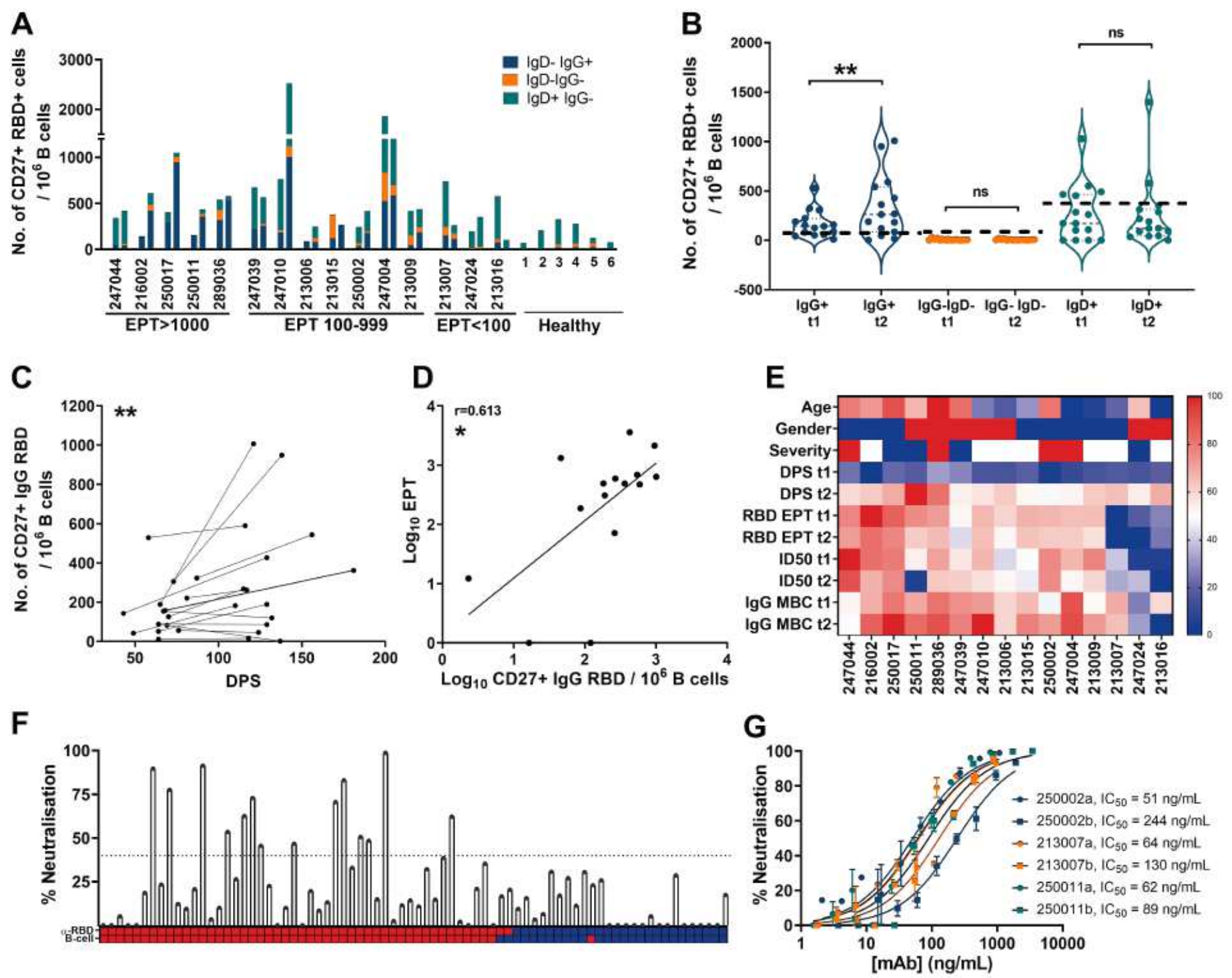

Figure 2

Memory B cell analysis and monoclonal antibody characteristics (A) Distribution of RBD specific Ig classes / $106 \mathrm{~B}$ cells across all the EPT groups. The first bar represents $\mathrm{t} 1$ and the second bar represents t2 of each SARS-CoV-2 participant. Healthy participants have one bar representing one timepoint. (B) Violin plots of Ig subclass comparison between $\mathrm{t} 1$ and t2. Healthy control cutoff (mean $+2 \times \mathrm{SD}$ ) are represented by the dotted black line. (C) Comparison of CD27+lgG+RBD+ B cells / $106 \mathrm{~B}$ cells between $\mathrm{t} 1$ and $t 2$ showing an increase in frequencies (Wilcoxon matched-pairs signed rank test $p=0.0084$ ). (D) Correlation analysis between EPT and CD27+ IgG+ RBD+ B cells / 106 B cells during t2 (spearman's correlation, $p=0.017$ ). (E) Heat map of all subjects comparing age, gender, severity, DPS, EPT, ID50, $\mathrm{CD} 27+\lg G+\mathrm{RBD}+\mathrm{B}$ cells / $106 \mathrm{~B}$ cells from $\mathrm{t} 1$ and $\mathrm{t} 2$. (F) Neutralisation activity of all mAbs at 1/10 dilution. Dotted line represents $40 \%$ neutralisation cut-off. Heat map shows mAb RBD binding (red above and blue below cutoff) and IgG line shows whether the originating memory B cell was IgG+ (red) or IgD+ (blue). (G) Neutralisation plot of six mAbs identified from three SARS-CoV-2 participants at t2, each colour represents a participant. 


\section{Supplementary Files}

This is a list of supplementary files associated with this preprint. Click to download.

- Tables.pdf

- Supportinglnformation.pdf 